Rubin Gulaboski · Carlos M. Pereira

M. Natalia D. S. Cordeiro · Ivan Bogeski

Fernando Silva

\title{
Enzymatic formation of ions and their detection at a three-phase electrode
}

Received: 8 April 2005/ Revised: 11 April 2005/ Accepted: 12 April 2005 / Published online: 3 June 2005

(C) Springer-Verlag 2005

\begin{abstract}
An electrochemical method for the detection of enzymatically created anions is described that uses a thin-film electrode with decamethylferrocene as an electroactive redox probe. The enzymatic oxidation of glucose with enzyme glucose oxidase produces gluconic acid as a final product. The oxidation of decamethylferrocene dissolved in the thin-nitrobenzene film, that is spread on the working graphite electrode and submerged in the aqueous solution containing glucose and glucose oxidase, is followed by the up-take of gluconate anions from the aqueous phase to nitrobenzene. The peak currents of the square-wave voltammetric responses of that system are a linear function of the glucose concentration in the milimolar range from $0.1 \mathrm{mmol} / \mathrm{L}$ to $0.7 \mathrm{mmol} / \mathrm{L}\left(R^{2}=0.994\right)$.
\end{abstract}

Keywords Glucose - Enzymatic reactions - Biosensor · Thin-film electrode $\cdot$ Ion transfer $\cdot$ Decamethylferrocene

\section{Introduction}

The importance of the enzymatic reactions in biological processes is well recognized, and the features of these systems are intensively studied [1, 2, 3]. Among the techniques used for studying the enzymatic systems, the electrochemical techniques, indeed, take one of principal places [2]. Majority of the studies on enzymatic systems are devoted to the elucidation of the mechanisms of the enzymatic reactions, and the development of methods for the detection of the products of those reactions [1, 2,

R. Gulaboski · C. M. Pereira $(\bowtie) \cdot$ M. N. D. S. Cordeiro · F. Silva Departamento de Quimica, Faculdade do Ciências,

Universidade do Porto, 4169-007 Porto, Portugal

E-mail: cmpereir@fc.up.pt

Fax: + 351-2-26082959

I. Bogeski

Institute of Physiology, University of Saarland,

Homburg, Germany
3]. The last is a very important task, since it is fundamental in the industry of biosensors $[1,2]$. In this communication, we propose a new electrochemical manner for detecting the products of enzymatic reactions. It is based on the detection of the ionic products of an enzymatic reaction by a thin-film electrode, which is an alteration of a three-phase electrode [4, 5]. The threephase electrode is a system consisting of a graphite electrode, the surface of which is modified by an organic solution (water immiscible) of some electroactive compound (decamethylferrocene - dmfc, for example), immersed in a water electrolyte solution $[4,5,6]$. The electrochemical transformation of the electroactive redox probe in the organic phase disturbs the electroneutrality of the organic phase. An outcome of this is an ion transfer step across the water solution|organic phase interface in order of rebalancing the charge electroneutrality of the organic phase. A detailed and comprehensive description of the processes occurring at threephase electrodes can be found elsewhere $[4,5]$. The use of a three-phase electrode as a tool for detection of the ionic products of enzymatic reactions relies on following simplified reaction scheme:

$$
\begin{aligned}
\text { Substrate }+ \text { Enzyme } \leftrightarrow & \mathrm{C}^{+}+\mathrm{A}^{-} \\
& + \text {Enzyme (in the water solution) } \\
\mathrm{dmfc}_{(\text {org })}+\mathrm{A}_{(\mathrm{w})}^{-} \leftrightarrow & \mathrm{dmfc}_{(\text {org })}^{+}+\mathrm{A}_{(\text {org })}^{-} \\
& +e^{-}(\text {at a three-phase electrode })
\end{aligned}
$$

$\mathrm{C}^{+}$and $\mathrm{A}^{-}$are ions obtained from the dissociation of some of the final products of the enzymatic reaction. The scenario $1 \mathrm{~b}$ is possible to happen if the standard Gibbs energy of transfer of the anions $\mathrm{A}^{-}$(created via enzymatic reaction) from water to organic phase is smaller than the corresponding Gibbs energy of transfer of electrochemically generated $\mathrm{dmfc}^{+}$cations from organic phase to water. In that case, the three-phase electrode 
approach can be used as an effective tool for detection of the ionic product(s) of the enzymatic reaction 1a.

In this work, we present the abilities of the thin-film electrode, with $\mathrm{dmfc}$ as an electroactive probe, to serve as a detecting tool of the ionic products obtained from the enzymatic oxidation of glucose by the enzyme glucoseoxidase. The method is based on the transfer of gluconate anions across the water|nitrobenzene interface in order to rebalance the charge-electroneutrality in the nitrobenzene phase, which is disturbed by the electrochemical oxidation of the redox probe $(\mathrm{dmfc})$ dissolved in it. The gluconate anions are dissociation products of gluconic acid, which is obtained according to simplified reaction scheme (2).

Glucose $\stackrel{\text { Glucose Oxidase }+\mathrm{O}_{2}}{\longrightarrow}$ Gluconic acid $+\mathrm{H}_{2} \mathrm{O}_{2}$

It is worth noting that the detection, identification and quantification of glucose in the blood plays crucial role in the diagnosis and treatment of diabetes. The electrochemical methods for glucose detection and identification are among the most widespread because of their fast response, simplicity and accuracy $[7,8,9,10$, $11,12,13,14,15,16,17,18]$. Two of us [18] are coauthors of the most recent approach for amperometric detection of the glucose enzymatic products, based on an assisted proton transfer through gel-supported liquid|liquid interface. The approach for the detection of the glucose enzymatic products we present here is simple, fast, and consistent. It does not require additional modification and alteration of the set-up used by the studies of the common ion transfer reactions, described in previous publications $[4,5,6,19,20,21,22,23,24]$.

\section{Experimental}

All chemicals used were of analytical grade purity. Decamethylferrocene $(\mathrm{dmfc})$ and glucose oxidase (from Aspergillus niger $24 \mathrm{U} / \mathrm{mg}$ ) were purchased from Fluka, while all other chemicals used were products of MERCK. A $1 \mathrm{mmol} / \mathrm{L}$ nitrobenzene solution of $\mathrm{dmfc}$, containing also $50 \mathrm{mmol} / \mathrm{L}$ tetrabutylammonium tetrapheylborate $\left(\mathrm{TButN}^{+} \mathrm{TPB}^{-}\right.$), has been used for making a thin-film on the working electrode in the voltammetric experiments. A graphite electrode with surface area of $0.01 \mathrm{~cm}^{2}$, has been used as a working electrode. The reference electrode was $\mathrm{Ag} / \mathrm{AgCl}$ (sat. $\mathrm{KCl}$ ), while a $\mathrm{Pt}$ wire was as used as a counter electrode. Before spreading the organic solution on the electrode surface, the graphite electrode was abraded with $\mathrm{SiC}$ paper. One microlitre of the NB-solution of dmfc has been deposited on the graphite electrode, and the film was formed by spontaneous spreading. After drying for the period of 4-5 min, the film-modified electrode was submerged in the aqueous electrolyte solution, containing $0.1 \mathrm{~mol} / \mathrm{L}$ $\mathrm{Na}_{2} \mathrm{SO}_{4}, 1 \mu \mathrm{mol} / \mathrm{L}$ glucose oxidase, and varying the glucose concentration. The solution of glucose oxidase has been made by dissolving the adequate amount of the enzyme in Mili-Q water, and the stock solution was always kept in refrigerator. A fresh film has been made at the electrode for each concentration of glucose in the aqueous solution. In all experiments, no inert gas has been purged throughout the cell. Square-wave (SW) and cyclic voltammetry $(\mathrm{CV})$ were used as working techniques. All experiments were performed at room temperature.

\section{Results and discussion}

The electrochemical features of the compound decamethylferrocene ( $\mathrm{dmfc})$, when used as a redox probe in the three-phase electrode experiments, are well understood and documented $[4,5,6,19,20,21,22,23,24]$. In the last few years, the three-phase electrode technique has been promoted as a powerful tool for measuring the thermodynamics of ion transfer across the interfaces of two immiscible liquids $[4,5]$. This electrode consists of a graphite electrode, the surface of which is modified with a micro-droplet of water-immiscible organic solution of some neutral electroactive compound. Such modified, the electrode is immersed in an aqueous electrolyte solution, and a potential program is applied in a common three-electrode electrochemical cell [6]. The electrochemical transformation of the neutral electroactive compound in the organic phase disturbs the electroneutrality in the organic phase, provoking a simultaneous ion transfer across the liquid/liquid interface in order of restoring the electroneutrality in the organic phase. The thermodynamics of the ion transfer across the liquid|liquid interface can be determined in a very elegant and simple manner $[4,5,6]$. A detailed and comprehensive description of the processes occurring at the three-phase electrode, as well as its applications in the determination of the thermodynamics of ion transfer can be found elsewhere $[4,5]$. Though it has been proven that the three-phase electrode is a simple and powerful tool for measuring the thermodynamics of ion transfer, its application for kinetic measurements is more difficult, as that affords control of the currents what is only possible when the droplet volume and droplet size and shape can be easily reproduced. Other problem may arise from an uncompensated ohmic drop [20]. A very good choice for kinetic measurements of ion transfer across the liquid|liquid interface with the three-electrode set-up is, indeed, the thin-film electrode technique [24, $25,26,27,28,29]$. As recently shown by Mirčeski et al. [24] the application of the square-wave voltammetry in a thin-film modified electrode offers a simple way of studying the kinetics of ion transfer across the liquid|liquid interface.

The application of the thin-film electrode for glucose quantification, with $\mathrm{dmfc}$ as a dissolved electroactive probe, is possible only in an indirect way, since glucose is a neutral molecule. This indirect way should rely on the transfer of the gluconate anions across the water|nitrobenzene interface. Note that gluconate anions are ob- 
tained from dissociation of gluconic acid that is produced via oxidation of glucose according to reaction scheme (2). The schematic representation of the entire system in such case is given in Fig. 1. Shown in Fig. 2a are the cyclic consecutive voltammograms (10 scans) when the thin-film electrode was immersed in aqueous electrolyte solution containing $0.1 \mathrm{~mol} / \mathrm{L} \mathrm{Na}_{2} \mathrm{SO}_{4}$ and $1 \mu \mathrm{mol} / \mathrm{L}$ glucose oxidase. The diminishing of the voltammetric responses during consecutive cycling is an indication of electroactive material depletion from the organic phase, caused by the expulsion of generated decamethylferrocenium cations from the organic phase to the water. This always happens when highly hydrophilic anions, like sulphates, phosphates or fluorides are present in the aqueous phase $[4,5,6]$. The same picture is obtained when the thin-film electrode was submerged in aqueous solution containing $\mathrm{Na}_{2} \mathrm{SO}_{4}$ and glucose, or $\mathrm{Na}_{2} \mathrm{SO}_{4}$ itself (not shown). The consecutive cyclic voltammetric responses of the thin-film electrode that is immersed in aqueous solution containing simultaneously glucose and glucose oxidase are presented in Fig. $2 \mathrm{~b}$. The consecutive cycling in this case leads to the stable voltammograms, due to the transfer of anions from aqueous to the organic phase. Since in the system only sulphate and gluconate anions are present, and since sulphate anions are not transferable (see Fig. 2a), the transfer of gluconate anions from aqueous to the organic phase is responsible for the stability of the voltammograms presented in Fig. 2b. The overall coupled electron and ion transfer reaction in this case could be presented by following scheme:

$$
\begin{aligned}
& \operatorname{dmfc}_{(\mathrm{NB})}+\operatorname{gluconate}_{(\mathrm{w})}^{-} \leftrightarrow \operatorname{dmfc}_{(\mathrm{NB})}^{+} \\
& \quad+\operatorname{gluconate}_{(\mathrm{NB})}^{-}+e^{-},
\end{aligned}
$$

where the symbols " $w$ " and "NB" denote the water and nitrobenzene phase, respectively. It is worth noting that the estimated standard Gibbs energy of gluconate

Fig. 1 Schematic representation of the three-phase pyrolytic graphite electrode. The scheme shows the possible microstructure of a part of the electrode covered with an uneven film of an organic solvent that contains a neutral redox probe dmfc. $\mathrm{TButN}^{+} \mathrm{TPB}^{-}$is abbreviation for tetrabutylammonium tetraphenylborate. The electrode is submerged in aqueous solution containing glucose and glucose oxidase. With courtesy of Doc. Dr. Valentin Mirčeski from "Sts Kiril i Metodij" University, Skopje, Macedonia transfer across the water $/ \mathrm{NB}$ interface reads $31.00 \mathrm{~kJ} /$ mol.

Shown in the Fig. 3a are several square-wave voltammograms, obtained with the thin-film electrode, after consecutive additions of glucose in the aqueous phase. Increasing of the concentration of glucose is followed by proportional growing of the peak current of the square-wave voltammograms. The dependence of the peak currents of the square-wave voltammograms on the glucose concentration is shown in Fig. 3b. In the glucose concentration range from $0.1 \mathrm{mmol} / \mathrm{L}$ to $0.7 \mathrm{mmol} / \mathrm{L}$, the $\mathrm{SW}$ peak currents increases proportionally to the concentration of glucose, reaching a constant value for glucose concentrations higher than $0.8 \mathrm{mmol} / \mathrm{L}$. The equation corresponding to the linear part of the curve reads:

$$
\begin{aligned}
I_{\mathrm{p}} / \mu \mathrm{A}= & 50.30 \mu \mathrm{AmmolL}{ }^{-1} \times c(\text { glucose })_{\mathrm{w}} / \mathrm{mmolL}^{-1} \\
& +39.40 \mu \mathrm{A}\left(\mathrm{R}^{2}=0.994\right) .
\end{aligned}
$$

The intercept of the linear line corresponds to the current originating of the ion transfer of $\mathrm{dmfc}^{+}$cations from NB to water, when no gluconate ions are present in the system. This behaviour is in agreement with the theoretical predictions made by Komorsky-Lovrić et al. [30], which are based on the model analogous to that proposed by Girault et al. [31]. In a previous work [30], considering the reaction (III), the authors have shown that the theoretical SW peak currents depend on one dimensionless parameter $\rho$, defined as the ratio between the initial concentration of the transferable anions in the water phase and the initial concentration of the redox probe in the organic phase, i.e. $\rho=c\left(A^{-}\right)_{\mathrm{w}} /$ $c\left(\mathrm{dmfc}^{*}\right)_{\mathrm{NB}}$. When the value of the dimensionless parameter $\rho \geq 1$, the peak currents reach a limiting constant value. In the experiments corresponding to the starting point of plateau in Fig. $3 \mathrm{~b}$, the ratio between the glucose concentration in the water phase and the concentration of $\mathrm{dmfc}$ in the nitrobenzene is 0.8 , which is close to the theoretically predicted value [30]. The dependence of the SW peak potentials on the logarithm of the glucose concentrations in the water phase is given on Fig. 4. When the concentration of glucose in the aqueous phase is smaller than the initial $\mathrm{dmfc}$ concentration in nitrobenzene, than the SW peak potentials $E_{\mathrm{p}}$ shift in positive direction by increasing the glucose concentration, with slope of $55 \mathrm{mV} / \log \left[c(\text { glucose })_{\mathrm{w}}\right]$.

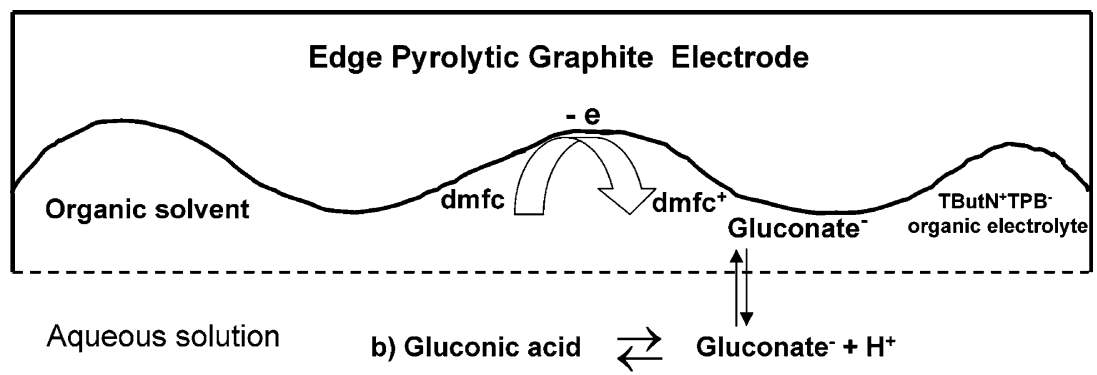

a) Glucose $\stackrel{\text { Gox }}{\longrightarrow}$ Gluconic acid 
Fig. 2 a Ten consecutive scans in cyclic voltammetry for the system of thin-film electrode containing $1 \mathrm{mmol} / \mathrm{L}$ dmfc and $50 \mathrm{mmol} / \mathrm{L}$ tetrabuthylamonium tetraphenylborate dissolved in nitrobenzene, that is immersed in aqueous electrolyte solution of $0.1 \mathrm{~mol} / \mathrm{L} \mathrm{Na}_{2} \mathrm{SO}_{4}$, containing also $1 \mu \mathrm{mol} / \mathrm{L}$ of enzyme glucose oxidase. The scan rate was $75 \mathrm{mV} / \mathrm{s}$. b Ten consecutive scans recorded under the same conditions like those in $\mathbf{a}$, in the additional presence of $0.1 \mathrm{mmol} / \mathrm{L}$ glucose in the aqueous phase
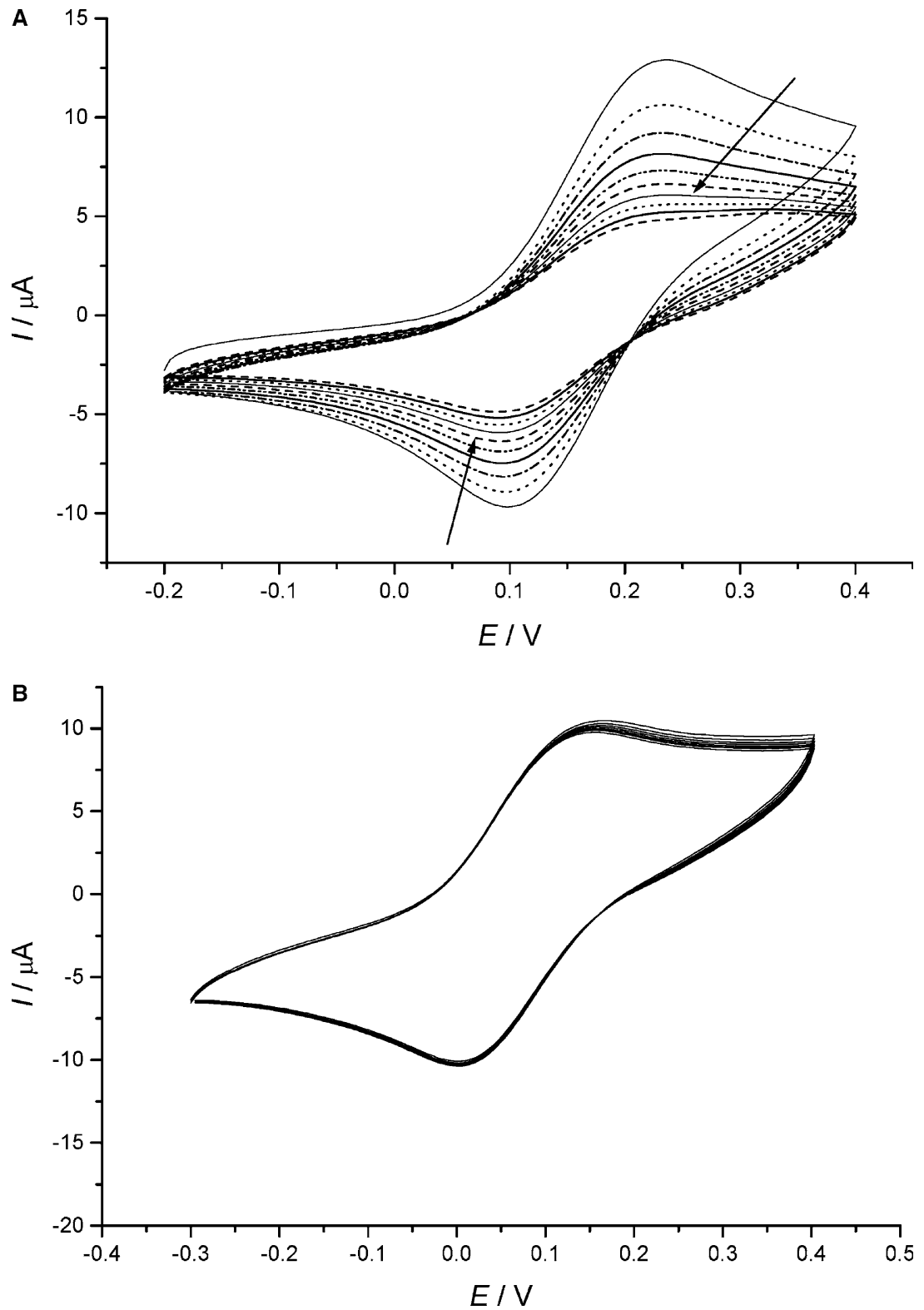

Oppositely, when the concentration of glucose is equal or higher than the initial concentration of $\mathrm{dmfc}$, the slope of the dependence $E_{\mathrm{p}}$ vs. $\log \left[c(\text { glucose })_{\mathrm{w}}\right]$ is $-54 \mathrm{mV}$. This behaviour is observed because the reaction (II) is of second order, and it is in complete agreement with the theoretical findings described in references $[4,30,31]$.

\section{Conclusions}

In this communication we show for the first time a new approach to follow an enzymatic reaction: the detection of ionic reaction products at a three-phase electrode. In this communication we show for the first time the abilities of the thin-film electrode, based on decamethylferrocene as a redox electroactive probe, to serve as an amperometric detector for quantification of the glucose enzymatic products. The method relies on the ionic catalytic currents due to the gluconate ion transfer across the water|nitrobenzene interface. These anions, obtained by the enzymatic oxidation of glucose, are crossing the water|nitrobenzene interface in order of restoring charge-electroneutrality of the organic phase, caused by oxidation of neutral decamethylferrocene present in the thin-film at the working electrode. The method is fast and simple, and further works are going to be done for its full characterization and improvement. It is worth mentioning that in the real samples, the presence of anions having smaller Gibbs energy of transfer than gluconate anions will always disfavour the transfer of gluconate anions $[4,5]$. The approach for the detection of the glucose enzymatic products we presented here does not require additional modification and 
Fig. 3 a Square-wave voltammograms of a thin-film electrode recorded in the presence of $1 \mu \mathrm{mol} / \mathrm{L}$ glucose oxidase in the aqueous phase and glucose in concentrations of: $0.1 \mathrm{mmol} / \mathrm{L}$ (1) $0.2 \mathrm{mmol} / \mathrm{L}$ (2); $0.3 \mathrm{mmol} / \mathrm{L} \mathrm{(3)} 0.4 \mathrm{mmol} / \mathrm{L}$ (4) and $0.5 \mathrm{mmol} / \mathrm{L}(5)$. SW frequency was $f=20 \mathrm{~Hz}, \mathrm{SW}$ amplitude was $E_{\mathrm{sw}}=50 \mathrm{mV}$, and scan increment d $E=2 \mathrm{mV}$. The other conditions were the same as those in Fig. 2.

b Dependence of the squarewave peak currents on the concentration of glucose in the aqueous phase
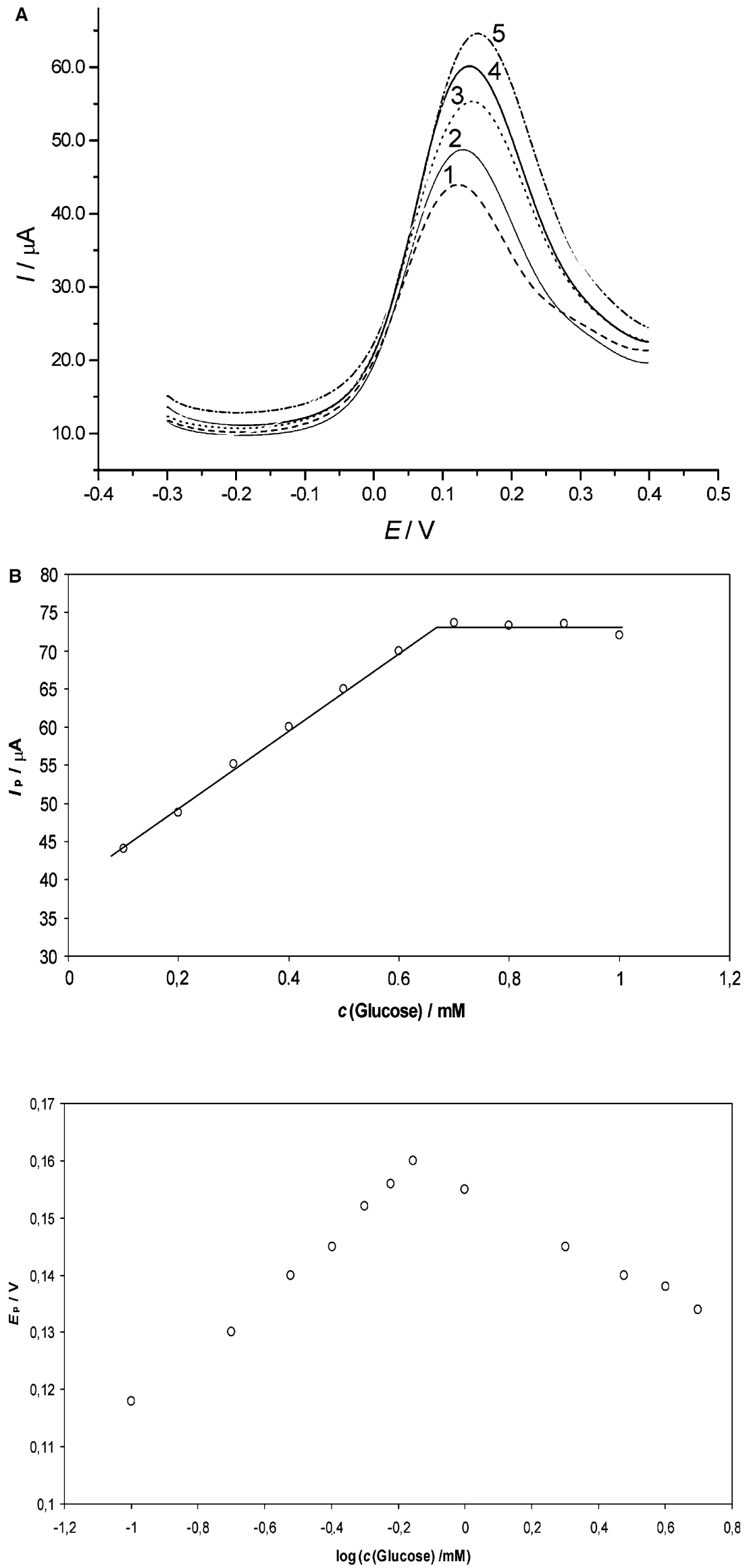

Fig. 4 Dependence of the square-wave peak potentials on the logarithm of the concentration of glucose in aqueous phase. The other conditions were same as those in Fig. 3a 
alteration of the set-up used by the studies of the common ion transfer reactions, described in previous publications $[4,5]$. We are currently expanding this new approach to the detection of other ionic products of enzymatic reactions.

Acknowledgments Rubin Gulaboski thanks Fundação para a Ciência e a Tecnologia (FCT) of Portugal for providing of a post. doc. fellowship (SFRH/BPD/14894/2004). The authors would like to thank FCT for financial support (CIQ L4 and FEDER for the project POCTI/QUI/42472/2001).

\section{References}

1. Walsh C (1978) Enzymatic reaction mechanisms. W.H. Freeman and Company, New York

2. Guilbault GG (1970) Enzymatic methods of analysis, (International series of monographs in analytical chemistry), 1st edn. Pergamon Press, London

3. Payne GF (1995) Coupling enzymatic reaction with adsorption. American Institute of Chemical Engineers

4. Scholz F, Schröder U, Gulaboski R (2005) Electrochemistry of immobilized particles and droplets. Springer, Berlin Heidelberg New York

5. Scholz F, Gulaboski R (2005) ChemPhysChem 6:16

6. Scholz F, Komorsky-Lovrić S, Lovrić M (2000) Electrochem Commun 2:112

7. Bard AJ, Faulkner LR (1980) Electrochemical methods. Wiley, New York

8. Jaffari SA, Turner APF (1995) Physiol Meas 16:1

9. Rechnits GA (1988) Chem Eng News 5:24
10. Updike SJ, Hicks GP (1967) Nature 214:986

11. Clark LC, Lyons C (1962) Ann NY Acad Sci 102:29

12. Guilbault GG, Lubrano GJ (1972) Anal Chim Acta 64:439

13. Vreeke MS, Yong KT, Heller A (1995) Anal Chem 67:4247

14. Horrocks BR, Schmidtke D, Heller A (1993) Anal Chem 65:3605

15. Aizawa M (1987) In: Ngo TT (ed) Electrochem sensors immunolog anal. Plenum, New York, pp 269-278

16. Gregg BA, Heller A (1991) J Phys Chem 95:5970

17. Gleria KD, Hill HAO, McNeil CJ (1986) Anal Chem 58:1203

18. Pereira CM, Oliveira JM, Silva RM, Silva F (2004) Anal Chem 76:5547

19. Gulaboski R, Scholz F (2003) J Phys Chem B 107:5650

20. Mirčeski V, Gulaboski R, Scholz F (2004) J Electroanal Chem 566:351

21. Gulaboski R, Galland A, Bouchard G, Caban K, Kretschmer A, Carrupt PA, Stojek Z, Girault HH, Scholz F (2004) J Phys Chem B 108:4565

22. Quentel F, Mirčeski V, L'Her M (2005) J Phys Chem B 109:1262

23. Banks CE, Davies TJ, Evans RG, Hignett G, Wain AJ, Lawrence NS, Wadhawan JD, Marken F, Compton RG (2003) Phys Chem Chem Phys 5:4053

24. Quentel F, Mirčeski V, L' Her M (2005) Anal Chem 77:1949

25. Shi C, Anson F (1998) Anal Chem 70:3114

26. Shi C, Anson F (1998) J Phys Chem B 102:9850

27. Shi C, Anson FC (1999) J Phys Chem B 103:6283

28. Chung TD, Anson FC (2001) Anal Chem 73:337

29. Shi C, Anson F (2001) J Phys Chem B 105:1047

30. Komorsky-Lovrić S, Lovrić M, Scholz F (2001) Collect Czech Chemm Commun 66:434

31. Stewart AA, Campbell JA, Girault HH (1990) Ber Bunsenges Phys Chem 94:83 